
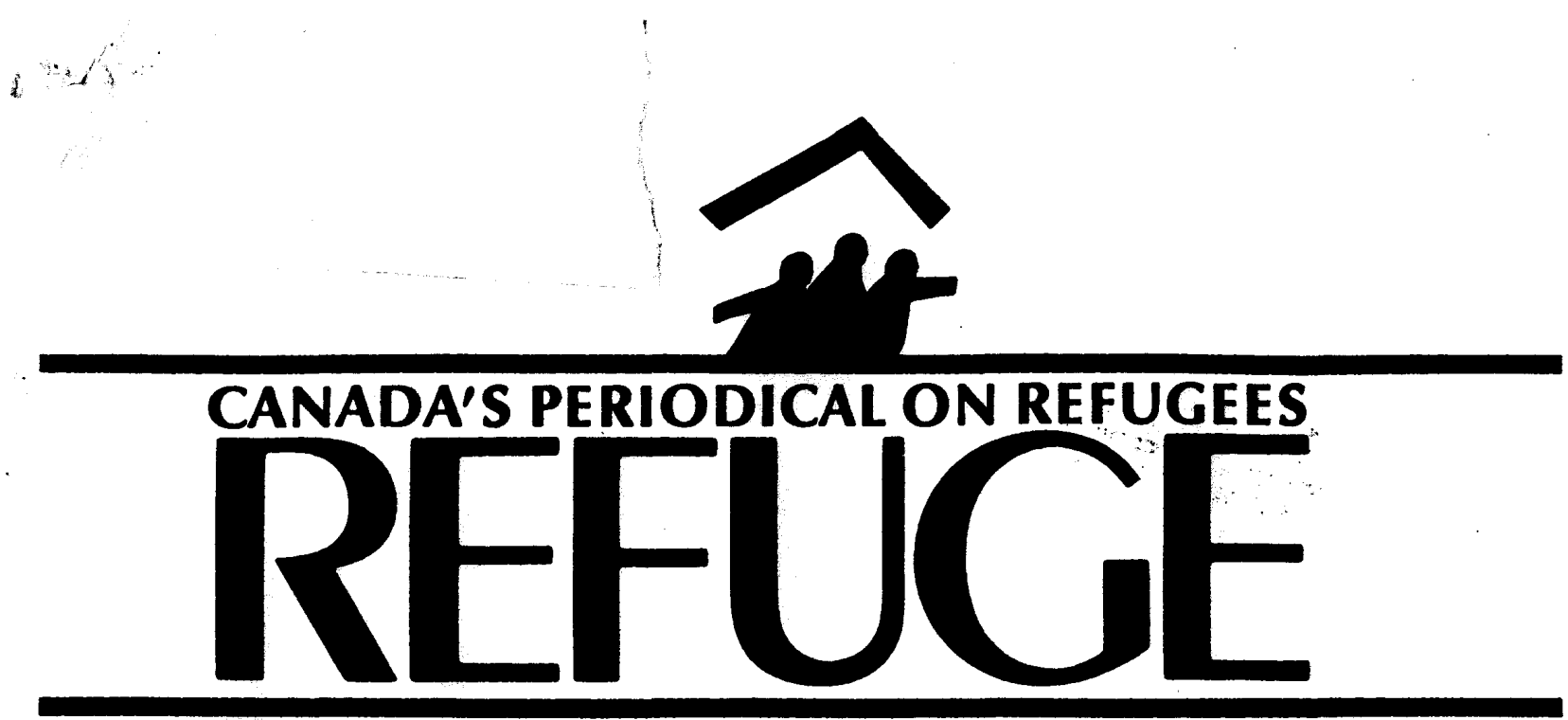

\title{
REFUGEES AROUND THE GLOBE
}

Refugees are a global problem. Sometimes, Refuge focuses on Canadian resettlement, policy or legal issues. At other times, we focus on regions - Afghanistan for example. A forthcoming Refuge will concentrateon the Horn of Africa.

In this issue, we provide a potpourri. The articles range from problems in the backlog to the plight of Somali refugees, Armenians in the Soviet Union and displaced refugees in the Gulf.

Ourfirstarticleby Edward OpokuDapaah provides a critical commentary on the current system for assessing individuals in the refugeebacklog. The criticism is mild compared to therecent salvo of the Canadian Council of Churches which accused the government of perpetuating the worst human rights abuses since the internment of Japanese-Canadians during World War II, worse presumably than thearrest of hundreds during the October crisis twenty years ago. Arul Aruliah analyzes the new refugeedetermination process not only to suggest we are creating a new "frontlog", but to suggest creative

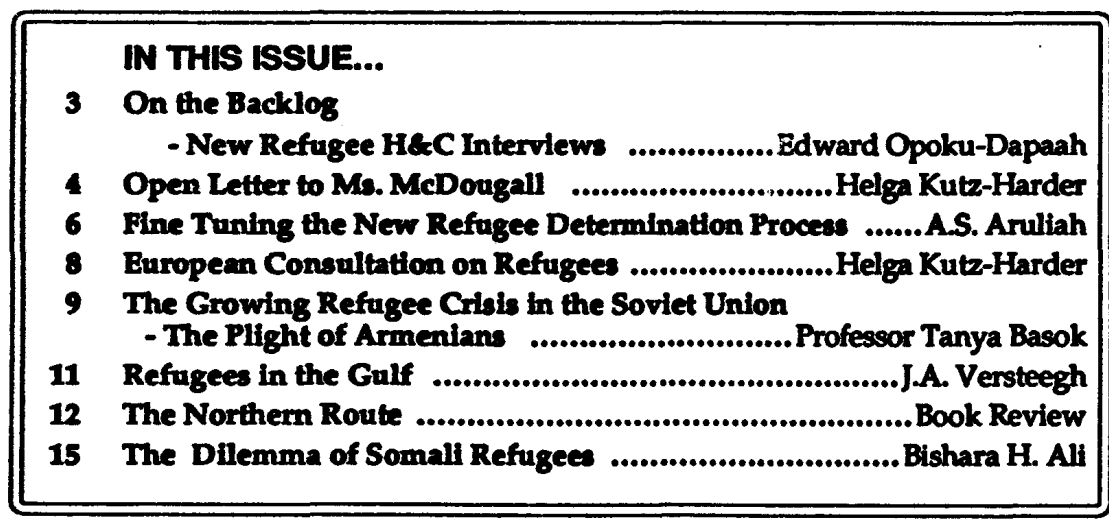

reforms to ensure the process remains both expeditious and fair.

What becomesclear in Helga KutzHarder's article is that the First World countries are meeting the challenge of new refugees by trying to raise their drawbridges and manning battle stations. Increasingly restrictive measures are likely to be the order of the day.

Yet areas emerge each day producing new waves of refugees - the Soviet Union, the Gulf. Academics are responding to these problems with more research, more conferences and more information, most of which reinforce positions adopted by those in the non-governmental and international sectors working to advance the cause of refugees. The two conferences at Oxford on Displaced Persons and Nutrition, the Singapore conference on migration, the York conferencedealing with Africa and with the Limits to Obligation, all attest to this increased attention.

If only words were deeds.

Howard Adelman, Editor 


\section{LETTERS:}

\section{ON SPONSORSHIP}

"..., there was a difference in perception when Poles or Ukrainians in Europe advance funds to Canada to facilitate their own sponsorships. Whereas some federal officials viewed this as a corrupt practice totally at odds with the intent of private sponsorship, Eastern Europeans saw this as a guarantee of successful reestablishment at great saving to Canadians."

[Refuge, Vol.9 No.4]

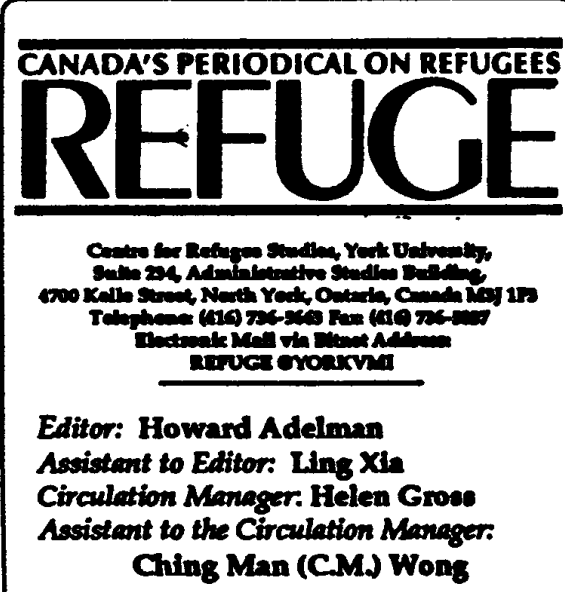

Rofugelo dodicated to the encouraguneat of

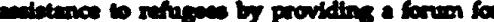

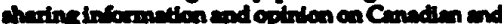

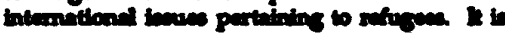

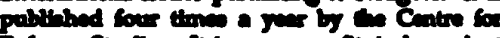

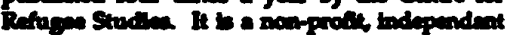

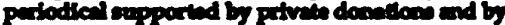

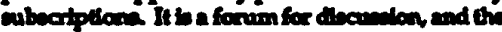

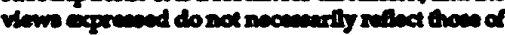
to funders or tinf.

Al mabeinl th Refuge mor be reproduced whout permisoton unleas copprighted of otherwise indicald Oredit should be given bo the

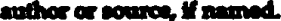

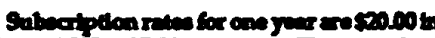

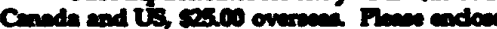
pejoneat with gour aries.

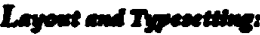

Alphe Dealdop Publiting cap easeres

Leco Deation:

Dreaderofint Co-operative Inc, Toroalo

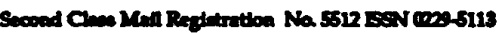

\section{Fortune and Fame on the Back of Refugees?}

To the Editor:

You appear to intimate that Ukrainian Immigrant Aid groups are involved in corrupt sponsorship practices and haveconnected us with questionable procedures used by other groups. This is without basis in fact.

For your information our organization co-ordinates cross-Canada sponsorshipe and has, over the past 18 years, established a system that successfully eliminates immigration lawyers, immigration consultants or any academics that attempt to make their fortune/fameon thebacks of unfortunate refugees.
We request that you retract/delete such statements.

B. A. Mykytiuk, President, Canadian Ukrainian Immigrant Aid Society

- Editor's Note: There was no intention to suggest that the Ukrainian immigrant or any other immigrant aid group was involved in corrupt sponsorship practices. The statement was merely that such allegations had been made. The reference to "corrupt" did not imply illegal behaviour but alleged practice contrary to the intent of the legislation. In any case, upon reflection, it would have been preferable to delete the phrase from the report.

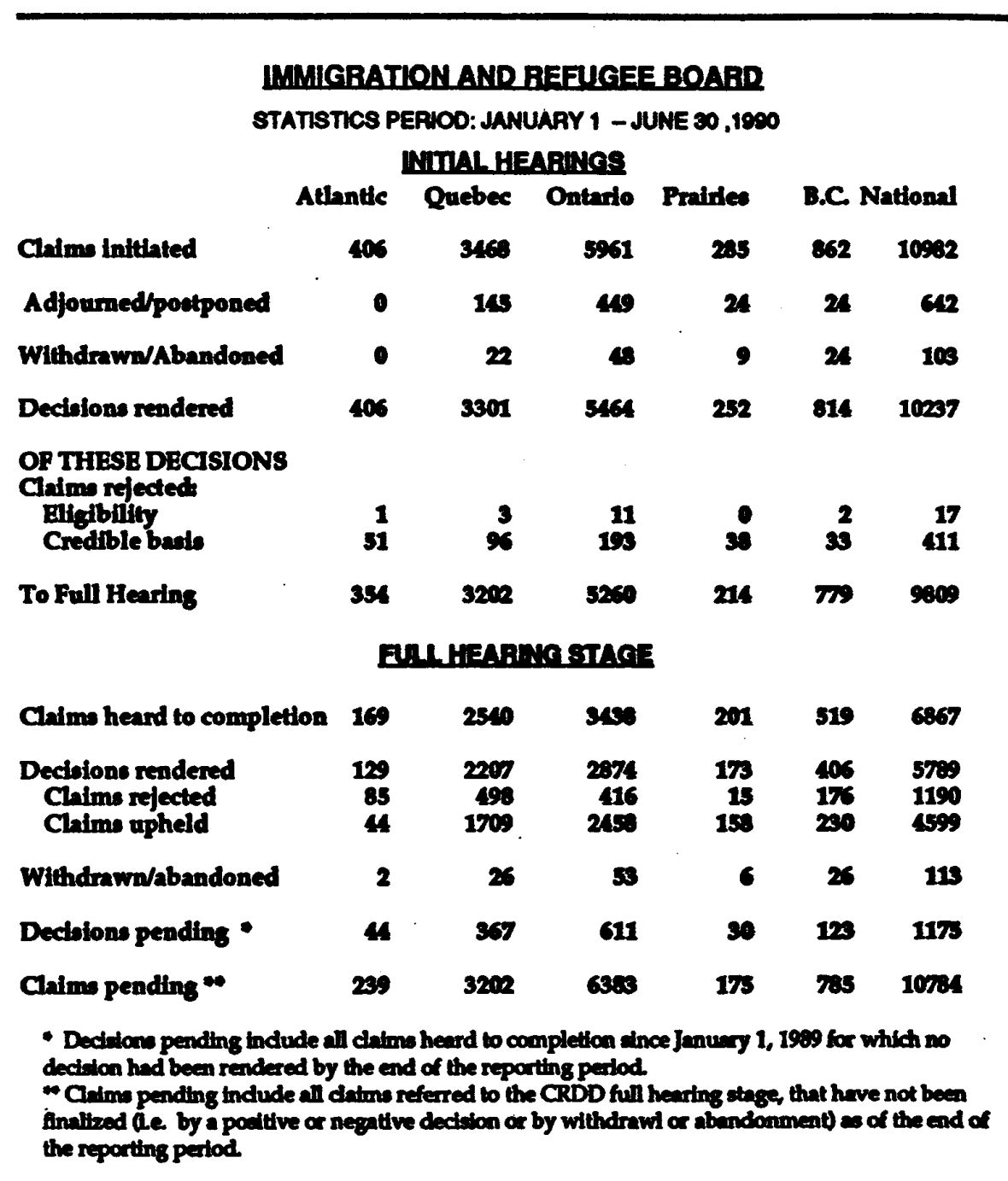

